\title{
Isolation and characterisation of a banana CYCD2;1 gene and its over-expression enhances root growth
}

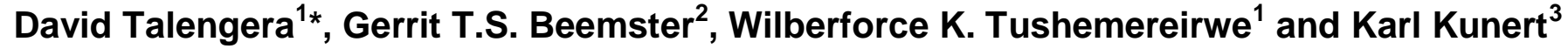 \\ ${ }^{1}$ National Banana Research Programme, National Agricultural Research Laboratories, P.O. Box 7065, Kampala, \\ Uganda. \\ ${ }^{2}$ Department of Biology, University of Antwerp, B-2020, Antwerp, Belgium. \\ ${ }^{3}$ Department of Plant Science, Forestry and Agricultural Biotechnology Institute, University of Pretoria, 0002 Pretoria, \\ South Africa.
}

Accepted 30 March, 2012

\begin{abstract}
Stimulation of the cell cycle by over-expression of Arabidopsis CyclinD2;1 enhanced growth in tobacco and rice, but not Arabidopsis. To broaden the range of species and to improve an important crop species for developing countries, a CyclinD2;1 homologue was isolated from an East African highland banana cultivar 'Nakasabira' (Musa spp., AAA group) and designated Musac;CYCD2;1 (Genebank accession no HQ839770). Musac;CYCD2;1 amino-acid sequence exhibited 40, 54, 57 and $57 \%$ identity with CYCD2;1 sequences of Arabidopsis, rice, maize and wheat, respectively. Overexpression of Musac;CYCD2;1 driven by the CaMV 35S promoter in cultivar 'Sukali ndizi' (AAB) resulted in transformed plants with no significant increase in total banana CYCD2;1 transcripts in the shoot, but up to 66-fold increase of total banana CYCD2;1 transcripts in roots. Correspondingly, transformed plants had no change in above-ground growth but produced longer main roots and more lateral roots under in vitro conditions. A deeper root system was observed in one transgenic line relative to non-transformed plants when grown in soil. Results demonstrate that a banana homologue of Arabidopsis CYCD2;1 can also enhance growth in a homologous background and the potential of enhancing banana root growth.
\end{abstract}

Key words: CyclinD2;1 gene, Musa spp., banana transformation, CyclinD2;1 over-expression, root growth.

\section{INTRODUCTION}

In plants and animals, D-cyclins (CYCD) control the cell G1/S transition and thus, entry into the cell cycle through their activation of the cyclin-dependent protein kinase (CDKA) (Nakagami et al., 2002). The active cyclin DCDKA complex initiates the Rb/E2F/DP pathway, leading to the transcription of genes required during $S$ phase (Inzé and De Veylder, 2006; Menges et al., 2007). Six Dtype cyclins have been so far identified in plants (Menges et al., 2007; Hu et al., 2010) and D-cyclins are expressed in response to sucrose providing a link between metabolic status and regulation of cell division (De Veylder et al., 1999; Riou-Khamlichi et al., 2000;

*Corresponding author. E-mail: talengera@kari.go.ug. Tel: +256 77 2695250. Fax: +256 414566381.
Nieuwland et al., 2009).

CYCD2;1 genes have been suggested as potential candidates for improving plant growth (den Boer and Murray, 2000; Inzé and De Veylder, 2006). When the Arabidopsis CYCD2;1 was over-expressed in tobacco under the control of the constitutive CaMV 35 S promoter, shoot and root growth were enhanced and the length of the cell-cycle G1 phase was reduced. Further, cell division and rate of leaf initiation were increased; the development duration from seedling to a mature plant was also shortened (Cockroft et al., 2000; Boucheron et al., 2005). Plant growth was stimulated when the Arabidopsis CYCD2;1 was over-expressed in transformed rice under the control of the maize ubiquitin1 promoter (Oh et al., 2008). Shoots and roots were wider, longer, and thicker in transformed rice seedlings. However, this effect on growth was not observed when 
transgenic rice seeds were grown in soil in the greenhouse; while in other species, growth stimulation by CYCD2 was not observed. In Arabidopsis, a homozygous T-DNA containing a single additional copy of genomic CYCD2;1 construct increased the rate of cell division markedly, but this did not result in increased growth rate and transformed plants grew normally (Zhou et al., 2003; Qi and John, 2007). Due to these contrasting reports, it is currently unpredictable if a particular over-expression construct will yield a growth stimulation in a given plant species and more detailed studies are required to support a growth stimulating role by CYCD2 over-expression.

Banana is a tropical giant perennial monocotyledonous herbaceous species of three to nine meters tall, with a pseudostem composed of compact overlapping leaf sheaths and a basal condensed stem (corm). Cultivated bananas have descended from natural crosses between two wild species, Musa acuminata Colla (AA; $2 n=22)$ and Musa balbisiana Colla (BB; $2 n=22)$ to give rise to lines with $A A, A B, A A A, A A B$ and $A B B$ genomic composition, respectively. Compared with diploids, triploid plants are generally more vigorous and high yielders (Purseglove, 1972). However, triploidy is associated with low gametic fertility and this greatly limits the application of crossbreeding to introgress important traits (Tenkouano et al., 2010). This trait largely prevents classic breeding approaches to improve commercial varieties. Consequently, genetic transformation offers a viable alternative. However, given the scanty Musa genomic information available, there is need to validate potentially useful genes identified in other species to use in banana.

In banana, higher biomass and early maturity are important above-ground growth traits, which together with bunch size, determines banana productivity (Swennen and De Langhe, 1985; Stover and Simmonds, 1987). Additionally, root development was found to positively influence aerial growth (Lecompte et al., 2002; Blomme et al., 2003). In this study, a banana cyclinD2;1 gene designated as $M$. acuminata CyclinD2;1 (Musac; CYCD2;1) was isolated and its over-expression was investigated to determine if this cyclin could enhance shoot and/or root growth in transgenic banana plants. We found that transformed banana plants had unaltered CYCD2;1 expression in the shoot tips and no difference in the above-ground growth compared to the controls. In contrast, the transgenics had elevated expression of the CYCD2;1 in the roots with a significantly enhanced in vitro root growth compared to the control and deeper roots when the plants were grown in soil. The results demonstrated the possibility of enhancing banana root growth through modification of cell cycle regulation.

\section{MATERIALS AND METHODS}

\section{RNA extraction and cDNA synthesis}

Total RNA was extracted from proliferating embryogenic cell suspensions of a Highland cooking banana ('Nakasabira'; Musa spp. AAA group) and a dessert banana ('Sukali ndizi'; AAB group). The cell suspension was initiated from immature male flowers as described by Côte et al. (1996). Similarly, total RNA was isolated from the shoot meristem of in vitro proliferating cultures of the wild progenitor of bananas 'Calcutta-4' (M. acuminata, AA, subspecies burmannicoides). RNA was isolated using the Nucleospin® plant kit (BD Biosciences Clontech, USA) following the manufacturer's instructions and treated with RNase-free DNAse I (Qiagen, Germany) to remove residual DNA. First strand cDNA was synthesized from $0.2 \mu \mathrm{g}$ of the total RNA using the Improm-IIM Reverse Transcription system (Promega) as described by the supplier.

Preparation of restricted enzyme-digested genomic DNA library

Genomic DNA was extracted from the cigar leaves using Dellaporta et al.'s (1983) method and was purified with a CFX ${ }^{\mathrm{TM}}$ DNA and gel band purification kit (Amersham Biosciences). Genomic library was prepared by restricting $3.5 \mu \mathrm{g}$ of DNA with enzymes Pvull to which adapters were ligated as described by Siebert et al. (1995).

\section{Cloning and sequencing banana $C Y C D 2 ; 1$}

Degenerate primers MaCD2FF and MaCD2REV (Table 1) were designed based on the conserved regions of CYCD2; 1 of maize cultivar Mo17 (accession AAL83926), wheat (AAQ08041), rice (BAB85522) and sugarcane (AAV28532). The primers were used with single stranded cDNA of cultivars 'Nakasabira' in a touchdown polymerase chain reaction (PCR) to amplify the initial cyclin fragment. The PCR reaction consisted of $94^{\circ} \mathrm{C}$ for $3 \mathrm{~min}, 15$ cycles consisting of $94^{\circ} \mathrm{C}$ for $45 \mathrm{~s}, 70^{\circ} \mathrm{C}$ for $45 \mathrm{~s}$, with $1^{\circ} \mathrm{C}$ reduction per cycle, $72^{\circ} \mathrm{C}$ for $1 \mathrm{~min}$, followed by 25 cycles of $94^{\circ} \mathrm{C}$ for $45 \mathrm{~s}, 58^{\circ} \mathrm{C}$ for $45 \mathrm{~s}, 72^{\circ} \mathrm{C}$ for $1 \mathrm{~min}$ and a final extension of DNA strands at $72^{\circ} \mathrm{C}$ for $7 \mathrm{~min}$.

To generate flanking regions of the first gene fragment, nested primers MagwFF1 and MagwFF2 (Table 1) corresponding to the 5'end and MagwRv1 and MagwRv2 (Table 1) matching the 3'-end were applied in a nested PCR reaction. The upstream 5'-end was amplified from the genomic library using primer MagwFF1 and the genome-walk adapter primer, AP1. Obtained PCR products were diluted 5 times and used as a template in a further PCR reaction with primer MagwFF2 and genome-walk adapter primer, AP2. PCR was conducted at $95^{\circ} \mathrm{C}$ for $5 \mathrm{~min}, 35$ cycles of $94^{\circ} \mathrm{C}$ for $30 \mathrm{~s}, 60^{\circ} \mathrm{C}$ for $30 \mathrm{~s}, 72^{\circ} \mathrm{C}$ for $1 \mathrm{~min}$, and a final extension at $72^{\circ} \mathrm{C}$ for $7 \mathrm{~min}$.

To isolate the $3^{\prime}$-end of the gene, Rapid Amplification of cDNA ends (RACE) technique was applied using the RACE kit (Invitrogen, USA) and nested PCR. In a first PCR reaction, gene specific primer

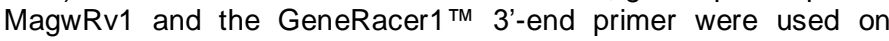
cDNA template. The resulting PCR product was then used as a template in a second PCR together with gene specific primer

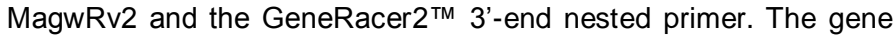
fragments were joined and submitted to the Expasy programme to generate an open reading frame (ORF) with ATG and TGA start and stop codon, respectively. Primers NKSCD-Fw and NKSCD-RV (Table 1) were designed at the 5' and 3' termini to amplify a final ORF from cDNA using a PCR programme of $95^{\circ} \mathrm{C}$ for $5 \mathrm{~min}, 35$ cycles of $94^{\circ} \mathrm{C}$ for $30 \mathrm{~s}, 60^{\circ} \mathrm{C}$ for $30 \mathrm{~s}, 72^{\circ} \mathrm{C}$ for $1 \mathrm{~min}$, and a final extension at $72^{\circ} \mathrm{C}$ for $7 \mathrm{~min}$.

All PCR products were cloned into Escherichia coli and the inserts were sequenced on an $\mathrm{ABI} 377$ sequencer. The full length CDNA was restricted from the TOPO cloning vector and cloned between a double CaMV35S promoter and a CaMV terminator sequence in vector pLBR19. The cyclin coding sequence with the promoter and terminator sequences was finally cloned into plasmid pBIN19 (Bevan, 1984) to create the expression vector pBin-35S- 
Table 1. PCR and qPCR primers used in the study.

\begin{tabular}{ll}
\hline Primer code & Sequence (5'-3') \\
\hline AP1 & GGATCCTAATACGACTCACTATAGGGC \\
AP2 & AATAGGGCTCGAGCGGC \\
BanActFw & CTGGTGATGGTGTGAGCCAC \\
BanActRv & CAGGGCAACGTAGGCAAGCT \\
GeneRacer1 & GCTGTCAACGATACGCTACGTAACG \\
GeneRacer2 & CGCTACGTAACGGCATGACACAGTG \\
MaCD2Fw & CGCCTCCATCCTGCTGtgygcngarga \\
MaCD2Rv & GAAGGAGCACGGGGTCacngcntgcat \\
MagwFF1 & ATCTCTCCTGATGGAGGAGTCCAACG \\
MagwFF2 & GCTCTCTCGACCAACAAGCTCAAC \\
MagwRv1 & TCTGTCCCTGGATTTACAGGTTGGTG \\
MagwRv2 & AGAGAATGGAGCTTCTGGTGATGAGC \\
NKSCD-Fw & ATGAGTCCAAGTTGTGACTGCG \\
NKSCD-Rv & TCATCTGGTTGTTTTCCTCCTCT \\
RTP1 & GGTTGTGGTGCACCTAGCA \\
RTP2 & GCTGACTGCTTCCTCATCAA \\
RTP3 & ACATTGTCAGGTGGGGAGTT \\
RTP4 & CCTTTTGTTCCACAGCAGATT \\
\hline
\end{tabular}

Musac;CYCD2;1. In addition, the plasmid had a selectable marker gene, neomycin phosphotransferase II (npt II) to facilitate selection of transformed cells.

\section{Bioinformatics}

Sequence of isolated gene fragment was characterized using a BLAST search against the NCBI GenBank database (http://www.ncbi.nlm.nih.gov/BLAST) and translated ExPasy programme (http://au.expasy.org/tools/). Cyclin D sequences were retrieved from available databases (http:iniprot.org, http:www.archieve.maizesequence.org). Phylogenic analysis of amino acid sequences was carried out using MEGA software (Version 3.1; Kumar et al., 2004). The cDNA and genomic sequences were aligned in MEGA software to analyse the introns in the genomic gene sequence.

\section{Plant transformation}

The expression vector was transformed into Agrobacterium tumefaciens (strain AGL1) cells using the heat shock technique (Sambrook et al., 1989). Transformation of banana cells of cultivar 'Sukali ndizi' and regeneration of plants was conducted as described by Ganapathi et al. (2001). Regenerated plants were multiplied on MS medium (Murashige and Skoog, 1962) supplemented with $5 \mathrm{mg} / \mathrm{L}$ BAP and $30 \mathrm{~g} / \mathrm{L}$ sucrose, $\mathrm{pH} 5.8$, according to the protocol of Vuylsteke (1989). Shoots were rooted on the same medium but devoid of growth regulators. Weaning and acclimatization of the plantlets were done following the procedure of Vuylsteke and Talengera (1998). PCR was conducted on isolated genomic DNA of regenerated putative transformed plants to confirm the presence of T-DNA in transformed plants using gene specific forward primer NKSCD-Fw and reverse primer NKSCD-Rv (Table 1).

\section{PCR analysis of Cyclin expression}

Total RNA was isolated from shoot tip, mature and young rolled leaf, and from the pulp of young fruits ( 14 days after appearance of the inflorescence). The derived cDNA and primers NKSCD-Fw and NKSCD-Rv (Table 1) were used in a semi-quantitative reverse transcription- polymerase chain reaction (RT-PCR) to determine tissue specific expression of banana $C Y C D 2 ; 1$. Actin was used as a reference gene to check equal loading between samples, using primers BanActFw and BanActRv (Table 1).

Real-time PCR was performed to determine total expression of banana CYCD2;1 (endogenous and transgene) in the shoot and root meristems. Primers RTP1 and RTP2 (Table 1) were designed to amplify a $251 \mathrm{bp}$ fragment of the banana $C Y C D 2 ; 1$. For real-time PCR, primers RTP3 and RTP4 were used to amplify a $107 \mathrm{bp}$ fragment of the Musa26SrRNA (AF399949) gene as a reference to normalize transcript amounts. Reactions were run in a Light Cycler® 480 (Roche, Switzerland) in $10 \mu$ volume containing $50 \mathrm{ng}$ cDNA, $5 \mu \mathrm{l}$ of preformed Sybr Green master mix and $0.5 \mu \mathrm{M}$ of each primer. Cycling conditions were $95^{\circ} \mathrm{C}$ for $10 \mathrm{~min}, 45$ cycles consisting of $95^{\circ} \mathrm{C}$ for $10 \mathrm{~s}, 60^{\circ} \mathrm{C}$ for $30 \mathrm{~s}$ and $72^{\circ} \mathrm{C}$ for $20 \mathrm{~s}$. Melting curves of PCR products were acquired by an extra cycle of $95^{\circ} \mathrm{C}$ for $30 \mathrm{~s}, 59^{\circ} \mathrm{C}$ for $1 \mathrm{~min}, 95^{\circ} \mathrm{C}$ for $10 \mathrm{~s}$ and $40^{\circ} \mathrm{C}$ for $30 \mathrm{~s}$. Relative quantification of banana CYCD2;1 transcription was determined using the relative standard curve method (Bustin et al., 2009) and relative $C Y C D 2 ; 1$ transcription in transformed plants was calculated relative to plants carrying an empty vector.

\section{Above-ground growth analysis}

Elongation of the ninth leaf of 3-month-old potted transformed and wild type plants was measured to determine the effect of the transgene on above-ground plant growth. Plant height was measured from the base of the plant to the junction of the petioles of the top-most leaves. Leaf length was measured daily from the base of the plant to the tip of the leaf. Measurements were 
performed daily at 9 am using a ruler and started at the time the leaf emerged from the plant crown, through unfurling, until leaf growth ceased. Laminar leaf area was determined by multiplying the blade length and width at the widest point by a factor of 0.8 (Kumar et al., 2002). Since post emergence increase in leaf length with time was exponential for at least the first four days, leaf growth rates were determined for this exponential growth by fitting a straight line through the log-transformed data.

\section{Root growth analysis}

In vitro growth of intact roots was measured using cultured rootless shoots growing on MS medium (Murashige and Skoog, 1962) that was supplemented with $5 \mathrm{mg} / \mathrm{L}$ benzyl aminopurine (BAP) and 30 $\mathrm{g} / \mathrm{L}$ sucrose, with a $\mathrm{pH}$ of 5.8 . Twenty single plantlets from each line were isolated and root formation was induced in $200 \mathrm{ml}$ glass baby food jars (Sigma, UK) containing $25 \mathrm{ml}$ of growth regulator-free MS medium. After 4 weeks, plantlets were removed from jars and the medium was washed off. Number of roots and length of the longest root on each plantlet were recorded.

Root growth rate was determined on root cultures derived from in vitro grown seedlings growing on MS medium. 1-Naphthaleneacetic acid (NAA) $(0.186 \mathrm{mg} / \mathrm{L})$ was added to induce primary root growth with minimal secondary root formation. Root tips $(1 \mathrm{~cm})$ were aseptically isolated and placed onto $10 \mathrm{~cm}$ Petri-dishes containing $25 \mathrm{ml}$ of culture medium comprising $\mathrm{N} 6$ basal salts, MS vitamins and $20 \mathrm{~g} / \mathrm{L}$ ascorbic acid, $40 \mathrm{~g} / \mathrm{L}$ sucrose, $0.2 \mathrm{~g} / \mathrm{L}$ yeast extract, $0.189 \mathrm{mg} / \mathrm{L}$ NAA and $2.3 \mathrm{~g} / \mathrm{L}$ phytagel (Duchefa Biochemie, The Netherlands). Five roots were cultured on each of the five replicate Petri-dishes for each line. Dishes were placed vertically and incubated in the dark at $27^{\circ} \mathrm{C}$. To monitor root growth, position of the root tip was marked every second day on the bottom of the Petri-dish. By measuring distance between the marks, the average daily growth was determined. After 18 days of culture, total root length and numbers of lateral roots formed were measured. Root growth of potted plants was determined in 6 months-old plants by removing potting substrate, washing roots under running tap water and documenting the root system with a digital camera.

\section{Data analysis}

Phenotype data was collected from twelve to twenty five replicates. Transcript data was generated from three individual plants per line from which three technical replicates were derived. Data were analyzed with the Statistical Analysis System, version 9.1 (SAS Institute, 2002). Leaf and root growth mean values and standard errors were generated using the general linear model (GLM). Ttests were performed on the relative transcript levels.

\section{RESULTS}

\section{Banana CYCD2;1 isolation and characterization}

To analyze the function of D2-type cyclins in banana, we first set out to isolate such genes from the banana genome. PCR amplification with degenerate primers MaCD2FF and MaCD2REV (Table 1) on single-stranded cDNA generated a 586 bp amplicon. Blasting this sequence against the GenBank database yielded a $C Y C D$ gene fragment $(\mathrm{E}-\mathrm{v}$ alue $=1 \mathrm{e}-62)$ containing the $\mathrm{N}$ terminal cyclin box. Genome walking to the 5'-end generated a $400 \mathrm{bp}$ fragment containing the ATG start codon. Race PCR to the 3'-end generated a $531 \mathrm{bp}$ fragment consisting the $\mathrm{C}$-terminus cyclin box (E-value = $3 e-35)$ and the TGA stop codon. PCR with primers NKSCD-Fw and NKSCD-Rv (Table 1) amplified an open reading frame of $1035 \mathrm{bp}$, from the three banana genotypes, encoding a protein of 344 amino acids of 63 $\mathrm{KDa}$ (Figure 1). The protein had a PEST motif between amino acids 1 to 33 (PESTFIND score +2.1). PEST motifs signal protein degradation and are characterized by a stretch of amino acids proline glutamic acid, serine, threonine, and aspartic acid. The same primers amplified a 2003 bp genomic sequence. Aligning the cDNA and genomic sequence revealed six exons in the genomic cyclin that are characteristic of CYCD2 and CYCD4 types. By domain analysis, we identified 131 and 90 cyclin conserved amino acid residues at the $\mathrm{N}$-terminal and C-terminal region of the protein, respectively. Similar to maize, rice, sugarcane and wheat CYCD2;1, the banana sequence contained the characteristic LxCXE, that is, LLCAE motif at the N-terminal (Figures 1 and 2). The banana cyclin had a unique motif, IWKVHAHY, within the cyclin N_domain (Figures 1 and 2). In addition, the $N$ domain had the $\mathrm{D}, \mathrm{K}, \mathrm{L}$ and $\mathrm{E}$ residues that are highly conserved and required for cyclin function (Menges et al., 2007). The cyclin protein sequences were identical for the banana $A A A$ and $A A B$ and $A A$ genomic groups studied. The Acuminata (AA) being a common genome, the isolated sequence was designated as $M$. acuminata CyclinD2;1 (Musac;CYCD2;1) according to the Plant Gene Nomenclature rules (Renaudin et al., 1996) and deposited to the GenBank under accession number HQ839770.

To determine a possible relationship between the banana cyclin sequence and cyclins from other plant species, a phylogenetic analysis was carried out. Musac;CYCD2;1 was localised as part of a monocot specific clade (Figure 3), with $40 \%$ identity to the Arabidopsis, $54 \%$ to rice, $57 \%$ to maize, $54 \%$ to sugarcane, and $57 \%$ to the wheat CYCD2 amino acid sequence.

\section{Expression of endogenous banana CYCD2;1}

Semi-quantitative RT-PCR detected highest transcript levels of banana CYCD2;1 in the shoot-tip (Figure 4). The levels were lower in young unrolled leaf while traces were detected in the fruits of banana plants. Consistent with the absence of cell division activity, CYCD2;1 transcription was below detection levels in the mature leaves.

\section{Expression of banana $C Y C D 2 ; 1$ in transformed plants}

To analyse the function of the banana CYCD2; 1 gene, transgenic plants over-expressing this gene were generated. The presence of the transgene in the 
1 ctc gec cgt ctt ttg tct cac tga gca ATG AGT CCA AGT TGT GAC

46 TGC GCC TCC TCT ATC CTC CTG TGC GCT GAG GAC AAC GAC AGC ATC

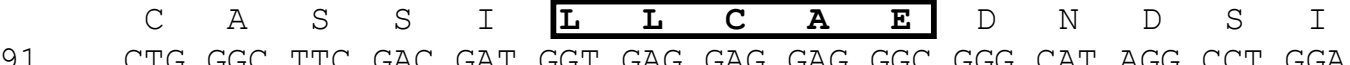

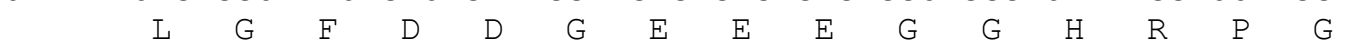

136 TGG GTT TCT GAA CCA AAA AGG TGC GAT TTT TAT GGG GAT ATC CTC

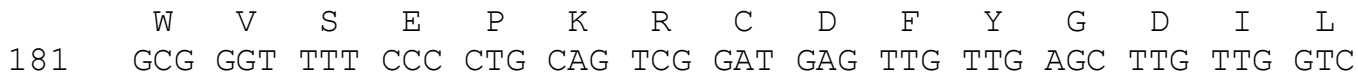

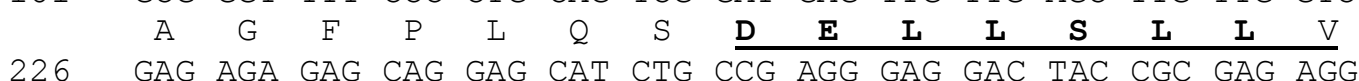

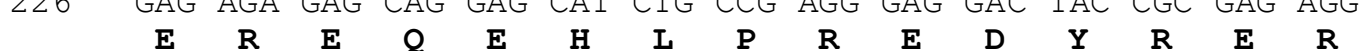

271 CTG TGT TCT GGg GCG TTG GAC TCC TCC ATC AGG AGA GAT GCT ATT $\begin{array}{llllllllllllllll}\mathrm{L} & \mathbf{C} & \mathbf{S} & \mathbf{G} & \mathbf{A} & \mathrm{L} & \mathbf{D} & \mathbf{S} & \mathbf{S} & \mathbf{I} & \mathbf{R} & \mathbf{R} & \mathbf{D} & \mathbf{A} & \mathbf{I} & 96\end{array}$

316 GAT TGG ATT TGG AAG GTT CAT GCT CAT TAC AAT TTT GGA CCA CTG

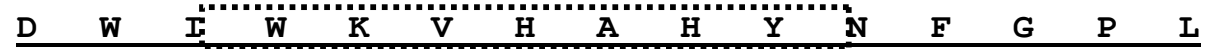

361 AGT GCC TAT TTA TCT GTA ÄAT TAC TTG GAT' ÄGG TTC CTC TCT TCC $\begin{array}{llllllllllllllll}\mathbf{S} & \mathbf{A} & \mathbf{Y} & \mathbf{L} & \mathbf{S} & \mathbf{V} & \mathbf{N} & \mathbf{Y} & \mathbf{L} & \mathbf{D} & \mathbf{R} & \mathbf{F} & \mathbf{L} & \mathbf{S} & \mathbf{S} & 126\end{array}$

406 TAT GAT CTC CCA CAA GGC AAG GCT TGG ATG ACA CAA CTA TTA TCT \begin{tabular}{lcccccccccccccc}
$\mathbf{Y}$ & $\mathbf{D}$ & $\mathbf{L}$ & $\mathbf{P}$ & $\mathbf{Q}$ & $\mathbf{G}$ & $\mathbf{K}$ & $\mathbf{A}$ & $\mathbf{W}$ & $\mathbf{M}$ & $\mathbf{T}$ & $\mathbf{Q}$ & $\mathbf{L}$ & $\mathbf{L}$ & $\mathbf{S}$ \\
\hline
\end{tabular}

451 GTG GCC TGC CTA TCT TTG GCT GCC AAG ATG GAG GAA ACT GAA GTT \begin{tabular}{ccccccccccccccc}
$\mathbf{v}$ & $\mathbf{A}$ & $\mathbf{C}$ & $\mathbf{L}$ & $\mathbf{S}$ & $\mathbf{L}$ & $\mathbf{A}$ & $\mathbf{A}$ & $\mathbf{K}$ & $\mathbf{M}$ & $\mathbf{E}$ & $\mathbf{E}$ & $\mathbf{T}$ & $\mathbf{E}$ & $\mathbf{V}$ \\
\hline $\mathrm{CCT}$ & CTG & TCC & CTG & GAT & TTA & CAG & GTT & GGT & GAG & GCA & AAA & TAT & ATA & TTT
\end{tabular}

$\begin{array}{ccccccccccccccccc}496 & \text { CCT } & \text { CTG } & \text { TCC } & \text { CTG } & \text { GAT } & \text { TTA } & \text { CAG } & \text { GTT } & \text { GGT } & \text { GAG } & \text { GCA } & \text { AAA } & \text { TAT } & \text { ATA } & \text { TTT } \\ & \mathbf{P} & \text { L } & \mathbf{S} & \text { L } & \text { D } & \text { L } & \mathbf{Q} & \mathbf{V} & \mathbf{G} & \mathbf{E} & \mathbf{A} & \mathbf{K} & \mathbf{Y} & \mathbf{I} & \mathbf{F}\end{array}$

541 GAA GGA AGG ACA ATT CAG AGA ATG GAG CTT CTG GTG ATG AGC ACC $\begin{array}{lllllllllllllll}\mathbf{E} & \mathbf{G} & \mathbf{R} & \mathbf{T} & \mathbf{I} & \mathbf{Q} & \mathbf{R} & \mathbf{M} & \mathbf{E} & \mathbf{L} & \mathbf{L} & \mathbf{V} & \mathbf{M} & \mathbf{S} & \mathbf{T}\end{array}$

586 CTC AAA TGG AGg ATG CAA GCT GTG ACT CCT TTC TCA TTC ATA GAT \begin{tabular}{lllllllllllllll}
$\mathrm{L}$ & $\mathbf{K}$ & $\mathbf{W}$ & $\mathbf{R}$ & $\mathbf{M}$ & $\mathbf{Q}$ & $\mathrm{A}$ & $\mathrm{V}$ & $\mathrm{T}$ & $P$ & $F$ & $S$ & $F$ & $I$ & $D$ \\
\hline
\end{tabular}

631 TTC TTC CTC CAC AAG TTC AAT GGT TGT GGT GCA CCT AGC AAG TTG

$676 \quad$\begin{tabular}{ccccccccccccccc}
$F$ & $F$ & $L$ & $H$ & $K$ & $F$ & $N$ & $G$ & $C$ & $G$ & $A$ & $P$ & $S$ & $K$ & $L$ \\
\hline \hline$C A$ & CTT & TCT & CGA & TCT & GCC & GAA & CTC & ATC & CTG & AGC & ACA & ATT & AGA & GGC
\end{tabular} \begin{tabular}{ccccccccccccccc}
$S$ & $L$ & $S$ & $R$ & $S$ & $A$ & $E$ & $L$ & $I$ & $L$ & $S$ & $T$ & $I$ & $R$ & $G$ \\
\hline ATT & GAT & TTC & CTA & GCA & TTC & AGA & CCC & TCA & GTA & ATT & TCT & GCA & GCC & ATT
\end{tabular} \begin{tabular}{ccccccccccccccc}
$I$ & $D$ & $F$ & $L$ & $A$ & $F$ & $R$ & $P$ & $S$ & $V$ & $I$ & $S$ & $A$ & $A$ & $I$ \\
\hline GCA & CTG & TTG & GTT & TTG & GGA & GAA & ACC & CAG & ATT & GTG & GAT & GTT & GAG & GAG
\end{tabular}

766 GCA CTG TTG GTT TTG GGA GAA ACC CAG ATT GTG GAT GTT GAG GAG

811 GCC TTG TCT TGT TGC TGT CAT GTA GCT AAG GAG GGG GTG TTG GGA \begin{tabular}{lllllllllllllll}
$A$ & $L$ & $S$ & $C$ & $C$ & $C$ & $H$ & $V$ & $A$ & $K$ & $E$ & $G$ & $V$ & $L$ & $G$ \\
\hline
\end{tabular}

856 TGT TAT GAA GTG ATT CAA GAC AAA GTA TTG ATG AGG AAg CAg TCA

901 GCC $\begin{array}{ccccccccccccccc}C & Y & E & V & I & Q & D & K & V & L & M & R & K & Q & S \\ & \text { GAC } & \text { CTA } & \text { GTC } & \text { TCC } & \text { TCG } & \text { GTA } & \text { TCC } & \text { TGT } & \text { GTG } & \text { CCC } & \text { CAA } & \text { AGC } & \text { CCT }\end{array}$

$\begin{array}{cccccccccccccccc} & \text { A } & \text { K } & \text { D } & \text { L } & \text { V } & \text { S } & \text { S } & \text { V } & \text { S } & \text { C } & \text { V } & \text { P } & \text { Q } & \text { S } & \text { P } \\ 946 & \text { GTT } & \text { GGG } & \text { GTG } & \text { TTG } & \text { CAT } & \text { GCT } & \text { GCA } & \text { TGC } & \text { CTG } & \text { AGC } & \text { TAC } & \text { AAG } & \text { AGT } & \text { GAT } & \text { GAT }\end{array}$ $\begin{array}{lllllllllllllll}V & G & V & L & H & A & A & C & L & S & Y & K & S & D & D\end{array}$

991 GCA ACT GTT GTG TCA CAT GCA ACA TGT CTT GGT CTC TCT CCA GCT

$\begin{array}{ccccccccccccccc}\text { A } & \text { T } & \text { V } & \text { V } & \text { S } & \text { H } & \text { A } & \text { T } & \text { C } & \text { L } & \text { G } & \text { L } & \text { S } & \text { P } & \text { A }\end{array}$ 6

Figure 1. Nucleotide (cDNA) and deduced amino acid sequence of Musac;CyclinD2;1. The retinoblastoma-related protein binding motif LxCxE (boxed in solid); 134 amino acid cyclin N_domain (bold and underlined); 87 amino acids Cyclin C_domain (italics and underlined); signature motif (boxed in dotted line) are indicated. Nucleotides are numbered on the left and amino acid residues are numbered on the right.

regenerated plants was validated by $P C R$ on isolated genomic DNA using primers NKSCD-Fw and NKSCD-Rv (Table 1). A $1035 \mathrm{bp}$ amplicon was generated that corresponded to cyclin cDNA integrated into the banana genome (Figure 5). These primers also amplified a 2033 bp product in transformed and control banana plants that represents the endogenous genomic intron-containing CYCD2;1 sequence. 


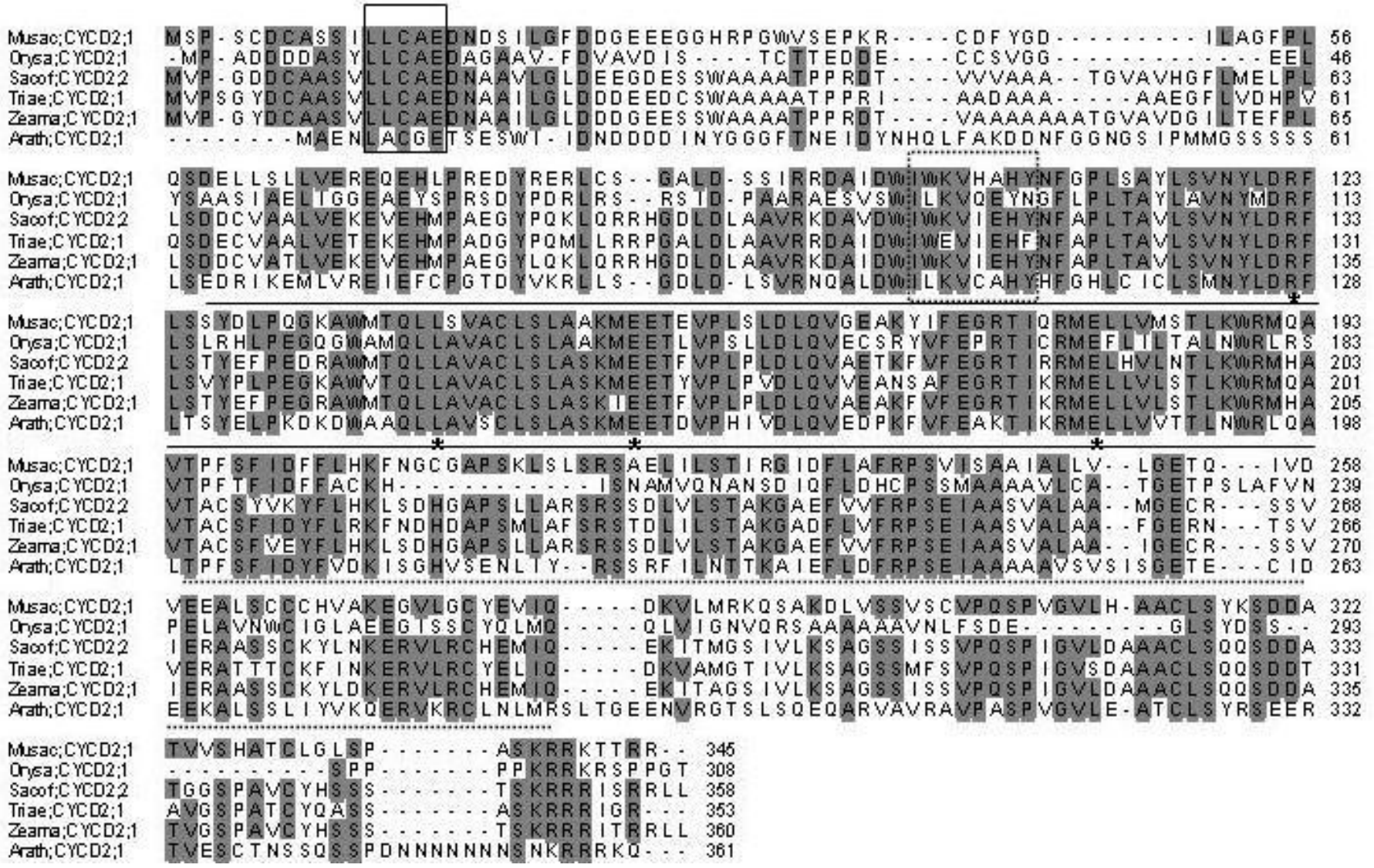

Figure 2. Multiple alignment of Musac;CYCD2;1 amino acid sequence with $C Y C D 2 ; 1$ amino acid sequences from other plant species: rice (Orysa, Oryza sativa), sugarcane (Sacof, Saccharum officinarum), wheat (Triae, Triticum aestivum), maize (Zeama, Zea mays) and Arabidopsis (Arath, Arabidopsis thaliana). The LxCxE binding motif (LLCAE; boxed), cyclin N domain (solid line), C domain (dotted line) and cyclin signature motif (boxed and dotted line), with the IWKVHAHY sequence specific for banana, are indicated. The four conserved residues required for cyclin function are underscored with stars. Identical amino acids are shaded in gray. Dashes indicate gaps required for maximal alignment of sequences.

Next, we determined the combined transcription levels of the exogenous banana CYCD2;1 transgene and of endogenous $C Y C D 2 ; 1$ in transformed plants by quantitative real-time PCR. There was no significant difference in transcription levels of $C Y C D 2 ; 1$ in shoot apices of transformed plants compared to control plants carrying only an empty-vector (Figure 6). However, significantly higher $(p<0.05) C Y C D 2 ; 1$ mRNA amounts were present in root apices of transformed banana plants when compared to the control carrying only an empty vector (Figure 6). Compared to the control plants, a 66-fold higher CYCD2;1 transcripts were recorded in transgenic plants of line NKS-30, a 10-fold in line NKS-10 and a 2fold in plants of line NKS-24 (Figure 6).

\section{Above-ground and root growth phenotypes}

To determine a possible phenotype change due to CYCD2;1 transgene transcription, we analyzed aboveground and root growth of the three transformed banana lines (NKS-30, 10, and 24) with different expression levels. With the exception of a small reduction in mature leaf area in the line with the lowest expression levels (NKS-24), under our experimental conditions, none of the transformed plants of these three lines showed a significant above-ground growth phenotype when compared to control plants (Table 2).

In contrast to shoot growth, root growth parameters from in vitro shoots were significantly enhanced for the line with the highest expression levels (NKS-30); both root number and length were increased compared to the un-transformed control (Table 3). Moreover, in vitro growth of isolated roots was similarly enhanced in line NKS-30; it had significantly longer roots and higher root growth rates than the control (Table 3; Figure 7). The number of lateral roots formed on these root segments varied from increased (line NKS-30), unaffected (NKS10), to decreased (NKS-24). However, this increase was less than the increase in root length, indicating that the density of laterals was reduced by CYCD2;1 overexpression. 


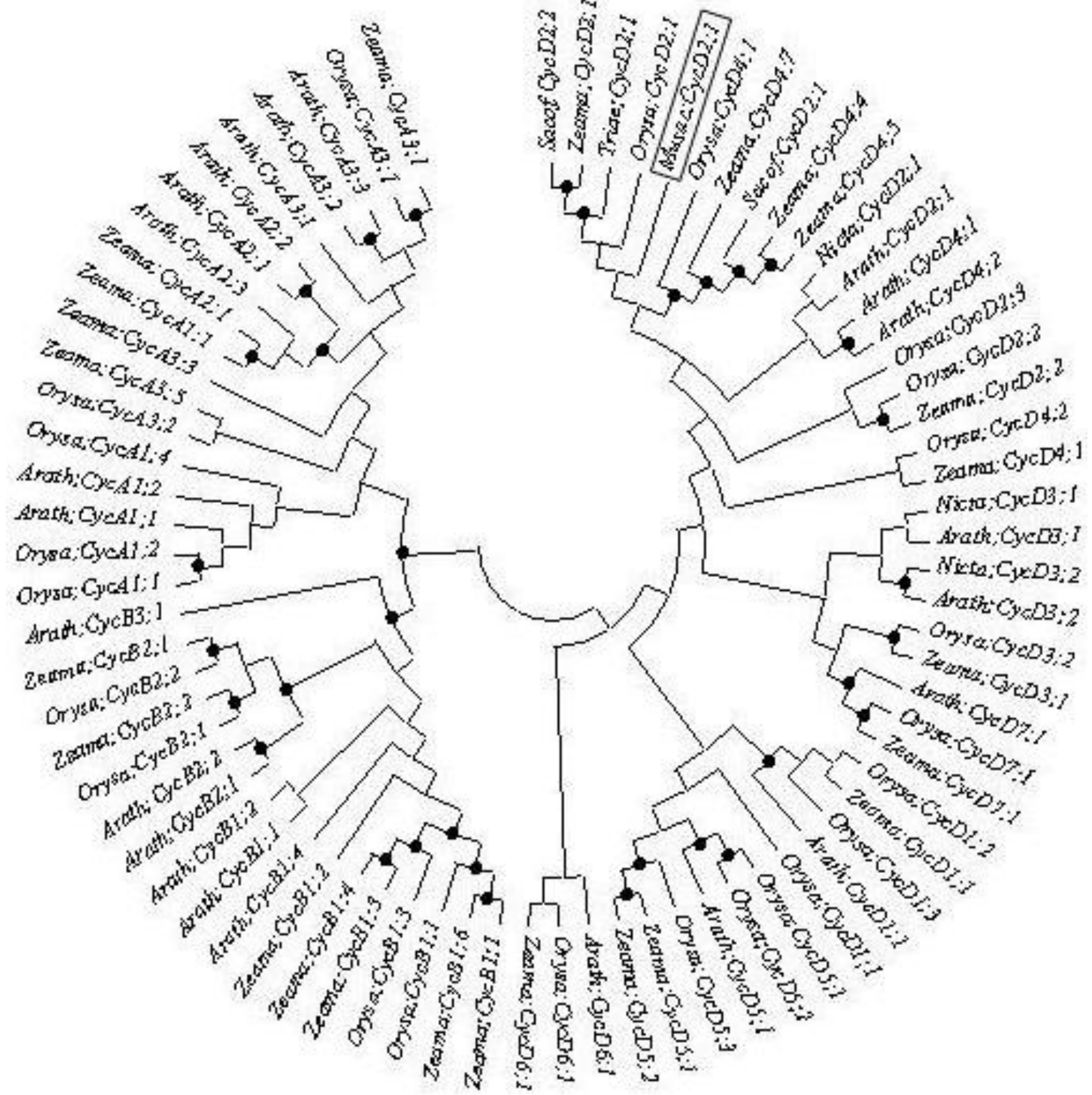

Figure 3. Phylogenic relationship of amino acid sequence of Musac;CYCD2;1 (boxed) with other plant cyclin sequences. Alignment was carried out using the program ClustalW. Phylogram was constructed using the neighbour-joining method. Nodes with bootstrap values above 70 are shown and are indicated as bullets. Arath represents Arabidopsis thaliana; Musac, Musa acuminata; Nicta, Nicotiana tabacum; Orysa, Oryza sativa; Sacof, Saccharum officinarum; Triae, Triticum aestivum; Zeama, Zea mays.

In general, plants of line NKS-30, which also had the highest banana $C Y C D 2 ; 1$ transcript amount, had the longest roots, the highest root growth rate and the highest number of roots when compared to all other plants tested. In addition, when plants of this line (NKS30) were transferred into soil and grown in the greenhouse, the root phenotype of deeper roots was maintained (Figure 7b).

\section{DISCUSSION}

In this study, the first cyclinD was isolated form a banana plant. The expression of the cyclin in the plant and the phenotype resulting from its overexpression were investigated. The predicted $\mathrm{N}$ and $\mathrm{C}$ amino acid domains constitute the binding site for the cyclin dependent kinases (CDK) while the LXCXE protein sequence is 


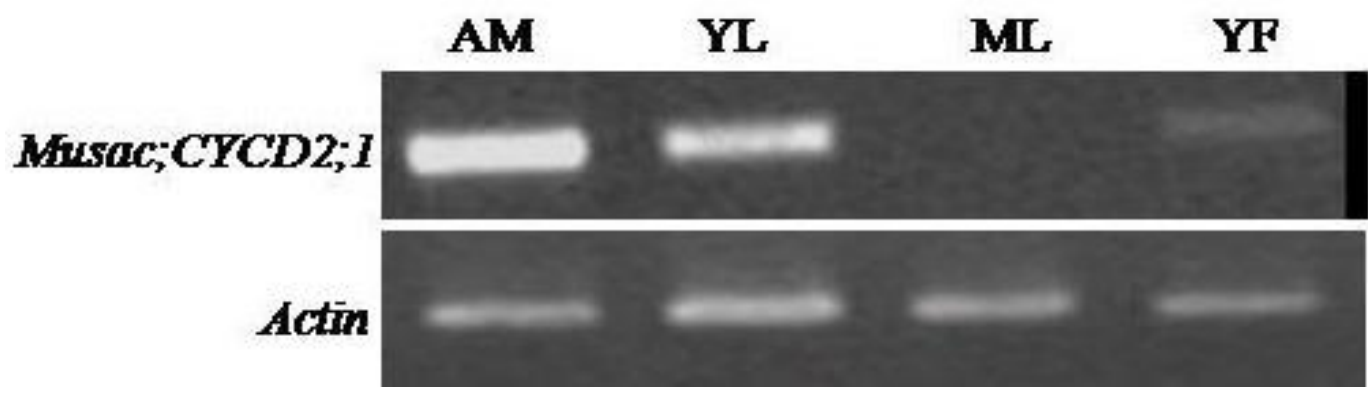

Figure 4. Transcription of endogenous Musac;CYCD2;1 in different banana tissues as detected by semi-quantitative RT-PCR. AM, apical shoot meristem; YL, young folded leaf at emergence; ML, mature leaf; YF, young fruit 14 days after flowering. Transcript amounts were normalized by amplification of the banana Actin gene.

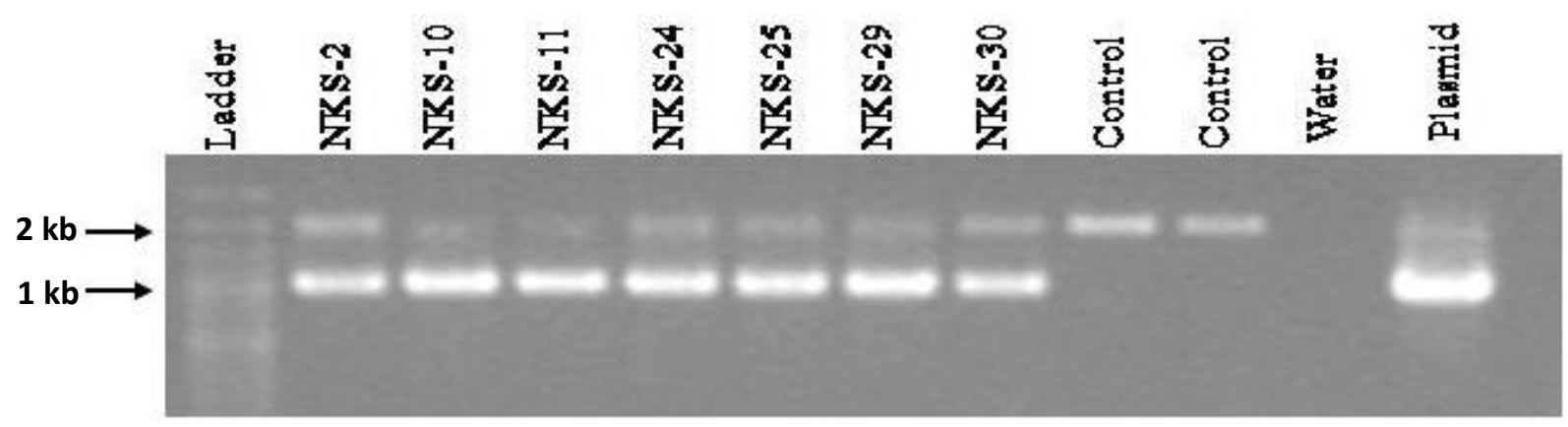

Figure 5. Detection by PCR of endogenous genomic (2 kb) and exogenous cDNA (1 kb) Musac;CYCD2; 1 sequence in transgenic banana plants (NKS-lines). Marker represents a $100 \mathrm{bp}$ DNA ladder. Control represents DNA from plants transformed only with an empty pBIN19 vector.

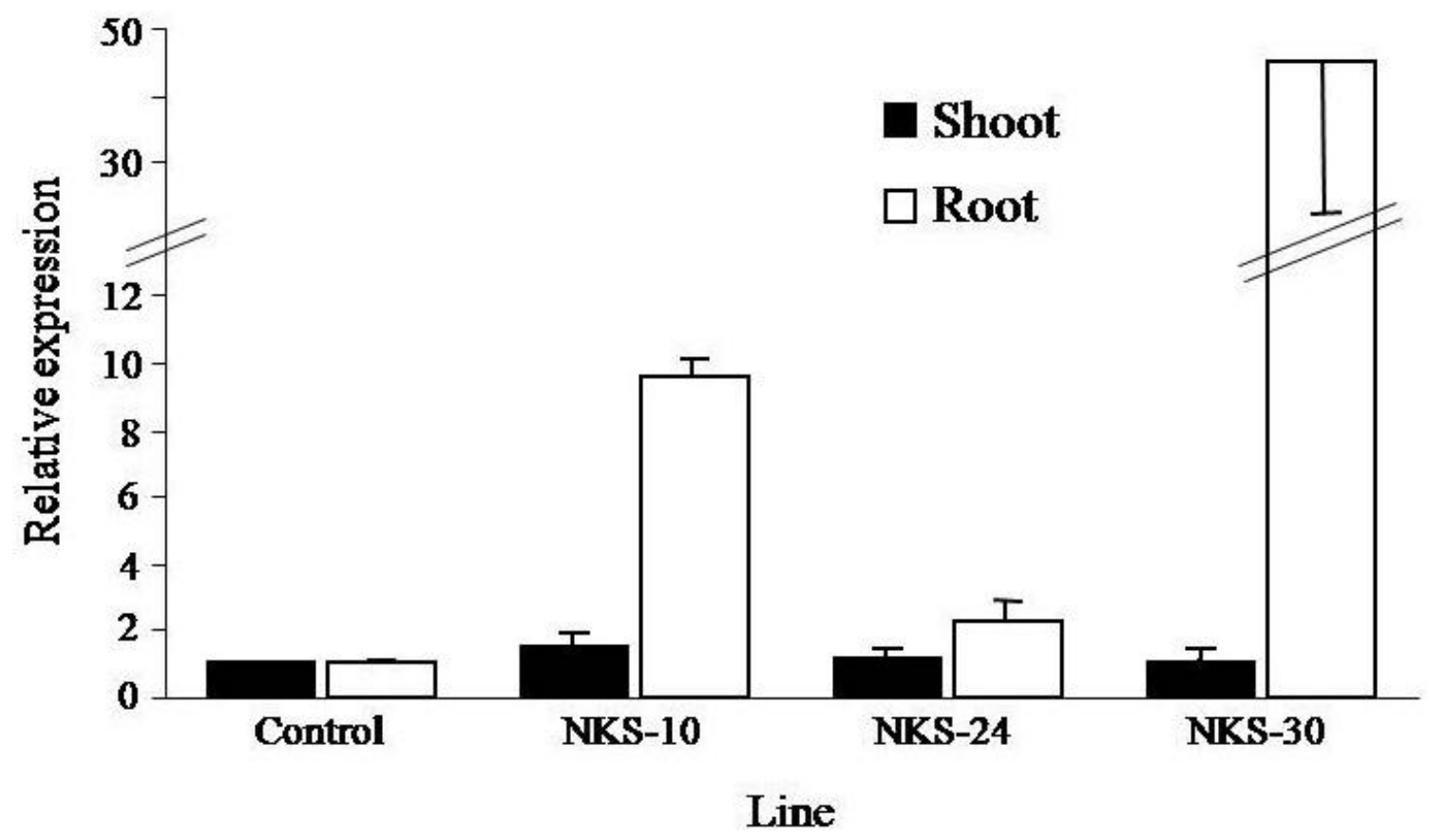

Figure 6. Transcription of exogenous Musac;CYCD2;1 in shoot and root apices of transgenic banana plants relative to the transcription of endogenous Musac;CYCD2;1 gene sequence in banana plants transformed with an empty pBIN19 vector. Values are the mean \pm SE of transcripts of three different plants. 
Table 2. Plant and leaf growth of transgenic banana plants over-expressing a banana $C Y C D 2 ; 1$ and non-transformed control plants.

\begin{tabular}{lccccc}
\hline Line & Plant height(cm) & Leaf opening(days) & Leaf elongation(days) & Leaf length(cm) & Mature leaf area(cm ${ }^{2}$ ) \\
\hline NKS-30 & $28.6 \pm 1.2^{\mathrm{a}}$ & $8.8 \pm 0.3^{\mathrm{a}}$ & $13.2 \pm 0.4^{\mathrm{a}}$ & $74.8 \pm 2.4^{\mathrm{a}}$ & $384.5 \pm 16.8^{\mathrm{a}}$ \\
NKS-10 & $29.2 \pm 0.5^{\mathrm{a}}$ & $8.8 \pm 0.3^{\mathrm{a}}$ & $13.7 \pm 0.4^{\mathrm{a}}$ & $73.9 \pm 1.2^{\mathrm{a}}$ & $396.4 \pm 10.2^{\mathrm{a}}$ \\
NKS-24 & $30.3 \pm 1.1^{\mathrm{a}}$ & $8.6 \pm 0.2^{\mathrm{a}}$ & $14.0 \pm 0.3^{\mathrm{a}}$ & $76.5 \pm 2.3^{\mathrm{a}}$ & $338.7 \pm 15.0^{\mathrm{b}}$ \\
Control & $29.1 \pm 0.6^{\mathrm{a}}$ & $9.2 \pm 0.2^{\mathrm{a}}$ & $14.0 \pm 0.4^{\mathrm{a}}$ & $75.2 \pm 1.7^{\mathrm{a}}$ & $417.5 \pm 13.1^{\mathrm{a}}$ \\
P-value & 0.513 & 0.261 & 0.431 & 0.794 & 0.001 \\
\hline
\end{tabular}

Values are the means \pm SE of 12 plants. Plant height was taken 8 weeks after potting the plants at which time other growth measurements were started. Duration of elongation, leaf length and leaf blade size were determined for mature leaves. Letters denote significance determined using ANOVA at $P=0.05$. Means followed by the same letter within the column are not significantly different.

Table 3. Root growth of transgenic banana plants over-expressing a banana cyclinD2;1 and non-transformed control plants.

\begin{tabular}{lcccccc}
\hline \multirow{2}{*}{ Line } & \multicolumn{2}{c}{ Rooting of in vitro shoots $(\mathbf{n}=\mathbf{2 0})$} & & \multicolumn{3}{c}{ In vitro root cultures $(\mathbf{n}=\mathbf{2 5})$} \\
\cline { 2 - 3 } \cline { 5 - 6 } & Roots $($ number) & Root length $(\mathbf{m m})$ & & Length $(\mathbf{m m})$ & Growth rate $(\mathbf{m m} /$ day) & Lateral roots (number) \\
\hline NKS-30 & $7.9 \pm 0.2^{\mathrm{a}}$ & $156 \pm 9^{\mathrm{a}}$ & & $35.3 \pm 1.9^{\mathrm{a}}$ & $2.1 \pm 0.1^{\mathrm{a}}$ & $21.5 \pm 1.8^{\mathrm{a}}$ \\
NKS-10 & $5.2 \pm 0.4^{\mathrm{c}}$ & $128 \pm 7^{\mathrm{bc}}$ & & $18.1 \pm 1.2^{\mathrm{c}}$ & $1.1 \pm 0.1^{\mathrm{c}}$ & $14.2 \pm 1.1^{\mathrm{a}}$ \\
NKS-24 & $4.0 \pm 0.2^{\mathrm{c}}$ & $112 \pm 9^{\mathrm{c}}$ & & $26.1 \pm 2.2^{\mathrm{b}}$ & $1.5 \pm 0.1^{\mathrm{b}}$ & $6.4 \pm 1.6^{\mathrm{b}}$ \\
Control & $6.3 \pm 0.4^{\mathrm{b}}$ & $145 \pm 7^{\mathrm{ab}}$ & & $17.1 \pm 1.1^{\mathrm{c}}$ & $1.1 \pm 0.1^{\mathrm{c}}$ & $15.5 \pm 1.1^{\mathrm{a}}$ \\
P-value & $<0.0001$ & 0.002 & & $<0.0001$ & $<0.0001$ & $<0.0001$ \\
\hline
\end{tabular}

Values are the means \pm SE of 20 intact roots and 25 isolated roots. Data on intact roots were taken after 3 wks of culturing the shoots, while for cultured roots the final length was determined after $18 \mathrm{~d}$ of growth. Letters denote significance determined using ANOVA at $P=0.05$. Means followed by the same letter within the column are not significantly different.

essential for the CyclinD-associated kinase to bind and phosphorylate the retinoblastoma-related (RBR) protein. These protein features are characteristic of CyclinD (Wang et al., 2004; Menges et al., 2007). Although there are proposals to consider CYCD2 and D4-types as one subgroup (Menges et al., 2007), phylogenic analysis grouped the isolated sequence closer to the CYCD2 of monocots than to CYCD4, confirming the isolated sequence as a D2-type cyclin.

In Arabidopsis, CYCD2 and D4 are structurally closer and their expression is similarly induced by sucrose and auxin (Riou-Khamlichi et al., 2000; Nieuwland et al., 2009). In rice, however, variation in transcriptional responses of the two cyclin groups to auxin suggested their functional differences (Guo et al., 2007). The IWKVHAHY sequence was unique for banana. Studies of cyclin gene structures have shown this motif to be highly variable and species-specific (Menges et al., 2007) and can be considered as a signature motif for the isolated banana cyclin.

The endogenous banana $C Y C D 2 ; 1$ transcription profile was consistent with the role of $C y c l i n D$ in cell division. In particular, the banana shoot apical meristem with the highest transcription is a region of active cell division to form the leaf primordia (Stover and Simmonds, 1987). Similar to other monocot plants, such as wheat (Beemster al et., 1996) and maize (Rymen et al., 2007), active cell division in banana occurs at the base of the young unfurled leaf at the time of emergence from the leaf crown. In addition, cells rapidly divide in early banana fruit development preceding cell expansion to form the storage tissue (Stover and Simmonds, 1987).

In this study, we could not find evidence for truncation of the exogenous $C Y C D 2 ; 1$ transgene in transformed banana plants. This is in contrast to a previous report of truncated CYCD2;1 transcripts in Arabidopsis (Qi and John, 2007). This implied that the transgene did not undergo further processing in the plant cells. Transformation did not lead to increased CYCD2;1 transcripts in shoot apices of soil-grown transgenic banana plants. The reason for differential transcription in shoot and root apices of transformed plants is still unclear. Future research has to show if higher amount of total $C Y C D 2 ; 1$ transcripts in the root apices is due to differential CaMV $35 S$ promoter activity. It could also be possible that the CYCD2;1 transgene was integrated into a root-specific active genome region of banana. Random mode of transgene insertion is widely known and transcription of a transgene is enhanced when the gene is inserted in an active region of a recipient genome (Lakshminarayan et al., 2000; Lee and Gelvin, 2008).

Also at this stage, the formation of chimeras or downregulation of cyclin expression in the shoot apices due to simultaneous transcription of an exogenous and endogenous CYCD2;1 sequence cannot be excluded.

There have been contrasting reports whether over-expression of $C Y C D 2 ; 1$ enhances plant growth. In tobacco, over-expression of the Arabidopsis CYCD2;1 enhanced 


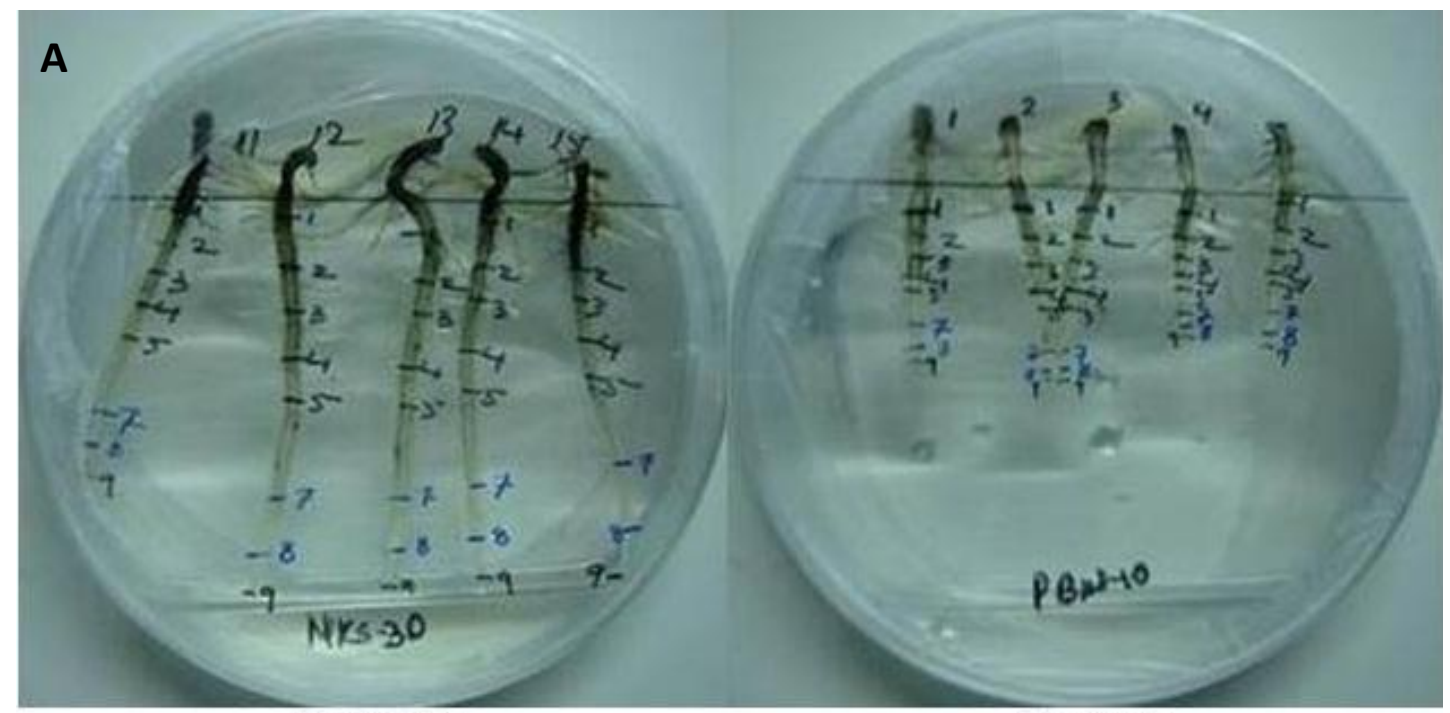

NKS-30

Control

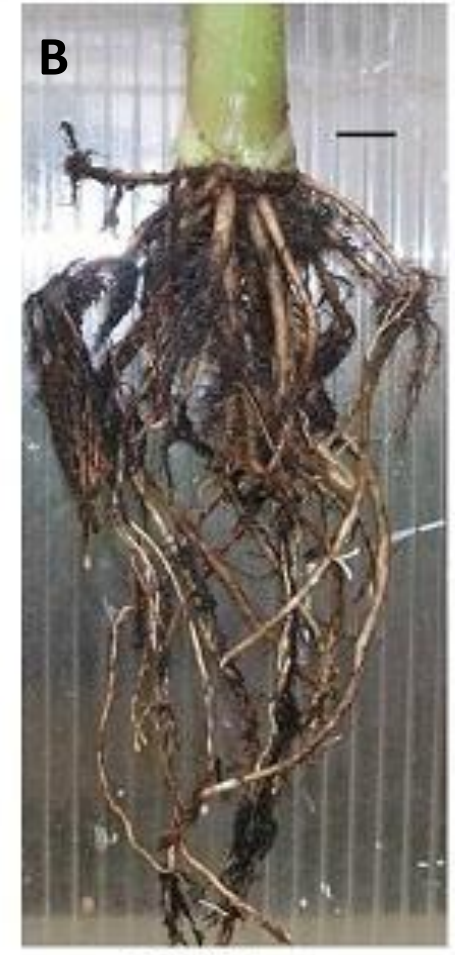

NKS-30

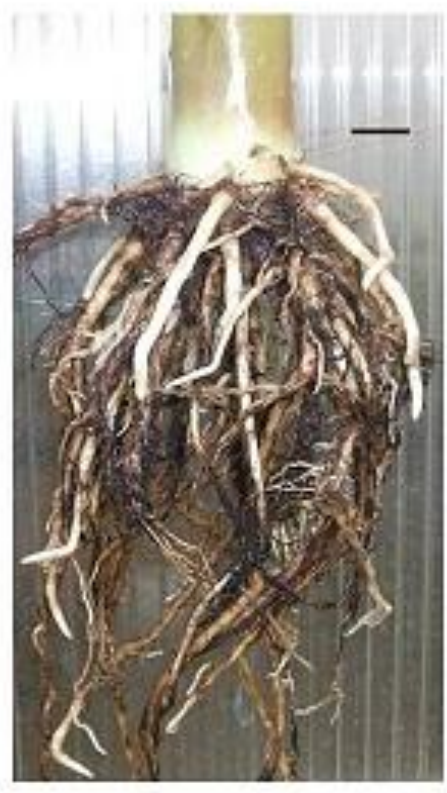

$\operatorname{Bar}=2 \mathrm{~cm}$

Figure 7. (A) Growth of isolated roots in vitro and (B) root growth in soil of transgenic banana plants (line NSK-30). Control plants were transformed only with the empty vector pBin19. Representative roots derived from five different plants are shown.

shoot and root growth with increased rate of leaf initiation and more rapid attainment of flowering size but with no change in final leaf size, internode length and leaf number (Cockroft et al., 2000; Boucheron et al., 2005). In the present study, over-expressing a banana CYCD2;1 sequence did not alter the expression of the gene in the shoot tips and did not affect the growth of the above ground parts of the transgenics. In contrast, the expression level in roots was significantly increased and in one line, a correlation between expression levels and growth was exhibited. It is known that the $35 \mathrm{~S}$ promoter is not as active and constitutive in monocotyledonous 
species as it is in dicotyledons (Chowdhury et al., 1997; Gupta et al., 2001). Therefore, using the monocotspecific ubiquitin promoter (Christensen and Quail, 1996) might result in more constitutively increased levels of the transgene, leading to an enhanced growth of both shoot and root. It may also be possible to use tissue or stage specific promoters from banana to construct plants with more specifically altered CYCD2;1 expression to specifically alter morphology so that they become more suitable for specific conditions. In rice, targeted transgene overexpression of OsNAC10 gene gave better drought tolerance in transgenic plants (Jeong et al., 2010). There is a positive correlation between root meristem size and root growth rates, and overexpression of D-type cyclins activated cell division in the root apex to promote seed germination (Rost and Bryant, 1996; Beemster and Baskin, 1998). Further, the apical and lateral meristem have been shown to posses the highest CYCD2;1 concentration and an elevated CYCD2;1 amount was shown to trigger cell division in the root apical meristem (Masubelele et al., 2005; Qi and John, 2007; Sanz et al., 2011). During the $G 1$ phase, sugar plays an important role in the expression and activity of D-type cyclins (RiouKhamlichi et al., 2000). In the present study, the sucrose in the in vitro root growth medium, in combination with the high transcription level of the banana CYCD2;1, might also have played a crucial role for a higher root number and longer roots in plants of line NKS-30. Further, root tissues are more sensitive to auxin, and Sanz et al. (2011) have demonstrated that CYCD2;1 enhances auxin action. Improved in vitro root growth of line NKS-30 plants was also related to deeper root growth of plants raised in soil under the greenhouse. Although improved root growth of in vitro grown rice plants was previously reported (Oh et al., 2008), improved growth was lost when seeds of transformed rice plants were grown in the soil. Therefore, future research has to determine the stability of this root growth phenotype in the transgenic bananas. A positive correlation between root and shoot biomass reported in banana (Lecompte et al., 2002; Blomme et al., 2003) was not exhibited in the transgenic plants under our experimental conditions. This could partly be attributed to the response of the two organs to the growth conditions in the greenhouse environment. Studies have shown that root growth is more responsive to temperature and soil moisture than shoots and cell elongation correspondingly proceeds more rapidly in roots (Walter et al., 2009). In addition, the stressful pot environment is not representative of the natural field environment for the plants to fully exhibit their physiology potential (Dosselaere et al., 2003). Therefore, field evaluation is needed to confirm the performance of the transgenics.

In general, deeper and elongated roots with a possible higher root volume would have several advantages for banana plants with an inherent shallow root system (Stover and Simmonds, 1987). Such a root system might confer a better and more rapid establishment of plants in the soil environment. An extensive root system might further contribute to the control yield loss arising from toppling of plants during windy and rainy seasons. In addition, such a long sought architectural trait (Tenkouano et al., 1998) could be helpful in the control of nematode damage. Furthermore, a deeper root system might help maintain the water status of the plant to avoid drought stress, which might be important in droughtprone areas in Sub-Saharan Africa. Although studies have been already conducted to understand the variability in the root system in the Musa germplasm (Blomme, 2003), employing this knowledge in conventional breeding schemes is still limited by the perpetual triploidy level and sterility of the commercial banana cultivars (Tenkouano et al., 2010).

\section{Conclusion}

In conclusion, we isolated a banana CYCD2;1 gene ortholog with a high identity to CYCD2;1 sequences of monocot plants. The isolated cyclin is transcribed in tissues associated with cell division. Banana plants of one line (NKS-30) with the highest total CYCD2;1 transcription had an enhanced root growth, indicating that cell cycle regulation might provide a tool to enhance root growth in banana. Testing plants of line NKS-30 under field conditions and maintaining this line as a mother line for further in vitro propagation will finally address the question of translating such root phenotype to field conditions and improving banana production particularly in moisture stress areas.

\section{REFERENCES}

Beemster GTS, Baskin TI (1998). Analysis of cell division and elongation underlying the developmental acceleration of root growth in Arabidopsis thaliana. Plant Physiol. 116: 515-1526.

Beemster GTS, Masle J, Williamson RE, Farquhar GD (1996). Effects of soil resistance to root penetration on leaf expansion in wheat (Triticum aestivum L.): Kinematic analysis of leaf elongation. J. Exp. Bot. 47: 1663-1678.

Bevan M (1984). Binary Agrobacterium vectors for plant transformation. Nucleic Acids Res. 12(22): 8711-8721.

Blomme G, Swennen R, Tenkouano A (2003). Assessment of genotypic variation in the root architecture of Musa spp. under field conditions. InfoMusa. 12(1): 24-29.

Boucheron E, Healy JHS, Bajon C, Sauvanet A, Rembur J, Noin M, Sekine M, Riou-Khamlichi C, Murray JAH, Van Onckelen H, Chriqui D (2005). Ectopic expression of Arabidopsis CYCD2 and CYCD3 in tobacco has distinct effects on the structural organization of the shoot apical meristem. J. Exp. Bot. 56(409): 123-134.

Bustin SA, Benes V, Garson JA, Hellemans J, Huggett J, Kubista M, Mueller R, Nolan T, Pfaffl MW, Shipley GL, Vandesompele J, Wittwer CT (2009). The MIQE Guidelines: Minimum information for publication of quantitative real-time PCR experiments. Clin. Chem. 55(4): 611-622.

Chowdhury MKU, Parveez GKA, Saleh NM (1997). Evaluation of five promoters for use in transformation of oil palm (Elaeis guineensis Jacq.). Plant Cell Rep. 16(5): 77-281.

Christensen AH, Quail PH (1996). Ubiquitin promoter-based vectors for 
high-level expression of selectable and/or screenable marker genes in monocotyledonous plants. Transgenic Res. 5(3): 213-218.

Cockroft CE, den Boer BGW, Healy JMS, Murray JAH (2000). Cyclin D control of growth rate in plants. Nature, 405: 575-579.

Cote FX, Domergue R, Monmarson S, Schwendiman J, Teisson C, Escalant JV (1996). Embryogenic cell suspensions from the male flower of Musa AAA cv. Grand Nain. Physiol. Plant. 97(2): 285-290.

Dellaporta SL, Wood J, Hicks JB (1983). A plant DNA mini preparation: version II. Plant Mol. Biol. Rep. 1(4): 19-21.

den Boer BGW, Murray JAH (2000). Control of plant growth and development through manipulation of cell-cycle genes. Curr. Opin. Biotech. 11: 138-145.

De Veylder L, Engler J, Burssens S, Manevski A, Lescure B, Van Montagu M, Engler G, Inze D (1999). A new D-type cyclin of Arabidopsis thaliana expressed during lateral root primordial formation. Planta, 208: 453-462.

Dosselaere N, Araya M, De Waele D (2003). Effect of pot volume on root growth, Radopholus similis reproductive potential and its damage on bananas. InfoMusa,12(1): 17-21.

Ganapathi TR, Higgs NS, Balint-Kurti PJ, Arntzen CJ, May GD, Van Eck JM (2001). Agrobacterium-mediated transformation of embryogenic cell suspensions of banana cultivar Rasthali (AAB). Plant Cell Rep. 20(2): 157-162.

Guo J, Song J, Wang F, Zhang XS (2007). Genome-wide identification and expression analysis of rice cell cycle genes. Plant Mol. Biol. 64(4): 349-360.

Gupta P, Raghuvanshi S, Tyagi AK (2001). Assessment of the efficiency of various gene promoters via biolistics in leaf and regenerating seed callus of millets, Eleusine coracana and Echinochloa crusgalli. Plant Biotech. 18(4): 275-282.

Hu X, Cheng X, Jiang H, Zhu S, Cheng B, Xiang Y (2010). Genomewide analysis of cyclins in maize (Zea mays). Genet. Mol. Res. 9(3): 1490-1503.

Inzé D, De Veylder $L$ (2006). Cell cycle regulation in plant development. Annu. Rev. Genet. 40: 77-105.

Jeong JS, Kim YS, Beak KH, Jung $\mathrm{H}$, Ha SH, Do Choi $\mathrm{Y}$, Kim M, Reuzea C, Kim JK (2010). Root-specific expression of OsNAC10 improves drought tolerance and grain yield in rice under field drought conditions. Plant Physiol. 153(1): 185-197.

Kumar N, Krishnamoorthy V, Nalina L, Soorianathasundharam K (2002). A new factor for estimating total leaf area in banana. InfoMusa, 11(2): 42-43.

Kumar S, Tamura K, Nei M (2004). MEGA3: Integrated software for molecular evolutionary genetics analysis and sequence alignment. Brief Bioinform. 5: 150-163.

Lakshminarayan MI, Kumpatla SP, Chandrasekharan MB, Hall CT (2000). Transgene silencing in monocots. Plant Mol. Biol. 43: 323346.

Lecompte F, Ozier-Lafontaine H, Pages L (2002). An analysis of growth rates and directions of growth of primary roots of field-grown banana trees in andisol at three levels of soil compaction. Agronomie, 23: 209-218.

Lee LY, Gelvin SB (2008). T-DNA binary vectors and systems. Plant Physiol. 146: 325-332.

Masubelele NH, Dewitte W, Menges M, Maughan S, Collins C, Huntley R, Nieuwland J, Scofield S, Murray JAH (2005). D-type cyclins activate division in the root apex to promote seed germination in Arabidopsis. Proc. Natl. Acad. Sci. USA. 102(43): 15694-15699.

Menges M, Pavesi G, Morandini P, Bögre L, Murray JMH (2007). Genomic organization and evolutionary conservation of plant D-type cyclins. Plant Physiol. 145: 1558-1576.

Murashige T, Skoog FA (1962). A revised medium for rapid growth and bioassay with tobacco tissue cultures. Physiol. Plant. 15: 473-497.

Nakagami H, Kawamura K, Sugisaka K, Sekine M, Shinmyo A (2002). Phosphorylation of retinoblastoma-related protein by the cyclin D/cyclin-dependent kinase complex is activated at the G1/S-phase transition in tobacco. Plant Cell. 14(8): 1847-1857.

Nieuwland J, Maughan S, Dewitte W, Scofield S, Sanz L, Murray JAH (2009). The D-type cyclin CYCD4;1 modulates lateral root density in Arabidopsis by affecting the basal meristem region. Proc. Natl. Acad. Sci. USA. 106(52): 22528-22533.
Oh SE, Kim SJ, Shic Kim YS, Park SH, Ha SH, Kim JK (2008). Arabidopsis cyclin D2 expressed in rice forms a functional cyclindependent kinase complex that enhances seedling growth. Plant Biotech. Rep. 2: 227-231.

Purseglove JW (1972). Tropical Crops: Monocotyledons Volume 1 and 2 combined. Longman, Essex.

Qi R, John PCL (2007). Expression of genomic AtCYCD2;1 in Arabidopsis induces cell division at smaller cell sizes: Implications for the control of plant growth. Plant. Physiol. 144: 1587-1597.

Renaudin JP, Doonan JH, Freeman D, Hashimoto J, Hirt H, Inze D, Jacobs T, Kouchi H, Rouze $P$, Sauter M, Savoure A, Sorrell DA, Sundaresan V, Murray JAH (1996). Plant cyclins: a unified nomenclature for plant A-, B- and D-type cyclins based on sequence organization. Plant. Mol. Biol. 32: 1003-1018.

Riou-Khamlichi C, Menges M, Healy SJM, Murray JAH (2000). Sugar control of the plant cell cycle: Differential regulation of Arabidopsis Dtype cyclin gene expression. Mol. Cell. Biol. 20(13): 4513-4521.

Rost TL, Bryant JA (1996). Root organization and gene expression patterns. J. Exp. Bot. 47(11): 1613-1628.

Rymen B, Fiorani F, Kartal F, Vandepoele K, Inzé D, Beemster GTS (2007). Cold nights impair leaf growth and cell cycle progression in maize through transcriptional changes of cell cycle genes. Plant. Physiol. 143: 1429-1438.

Sambrook J, Fritsch EF, Maniatis T (1989). Molecular cloning: A laboratory manual. Cold Spring Harbor Laboratory Press, New York.

Sanz L, Dewitte W, Forzani C, Patell F, Nieuwland J, Wen B, Quelhas $\mathrm{P}$, De Jager $\mathrm{S}$, Titmus $\mathrm{C}$, Campilho $\mathrm{A}$, Ren $\mathrm{H}$, Estelle $\mathrm{M}$, Wang $\mathrm{H}$, Murray JAH (2011). The Arabidopsis D-type cyclin CYCD2;1 and the inhibitor ICK2/KRP2 modulate auxin-induced lateral root formation. Plant Cell. 23: 641-660.

Siebert PD, Chenchik A, Kellogg DE, Lukyanov KA, Lukyanov SA (1995). An improved PCR method for walking in uncloned genomic DNA. Nucleic Acids Res. 23(6): 1087-1088.

Statistical analysis system (SAS) (2002) Institute Inc. Cary, NC.

Stover NW, Simmonds RH (1987). Bananas. Longman, Essex.

Swennen R, De Langhe E (1985). Growth parameters of yield of plantain (Musa cv. AAB). Ann. Bot. 56: 197-204.

Tenkouano A, Ortiz R, Vuylsteke D (1998). Combining ability for yield and plant phenology in plantain-derived populations. Euphytica, 104: 151-158.

Tenkouano A, Pillay M, Ortiz R (2010). Breeding techniques. In: Banana breeding: Progress and challenges, Eds. Pillay $M$ and Tenkouano $A$. Taylor and Francis Group, New York. pp. 181-202.

Vuylsteke D (1989). Shoot-tip culture for the propagation, conservation, and exchange of Musa germplasm. Practical manuals for handling crop germplasm in vitro. IITA, Ibadan.

Vuylsteke D, Talengera D (1998). Postflask management of micropropagated bananas and plantains. A manual on how to handle tissue-cultured banana and plantain plants. IITA, Ibadan.

Walter A, Silk WK, Schurr U (2009). Environmental effects on spatial and temporal patterns of leaf and root growth. Annu. Rev. Plant. Biol. 60: $279-30$

Wang G, Kong $\mathrm{H}$, Sun $\mathrm{Y}$, Zhang $\mathrm{X}$, Zhang W, Altman $\mathrm{N}$, de Pamphilis CW, Hong M (2004). Genome-wide analysis of the cyclin family in Arabidopsis comparative phylogenetic analysis of plant cyclin-like proteins. Plant. Physiol. 135: 1084-1099.

Zhou Y, Wang H, Gilmer S, Whitwill S, Fowke LC (2003). Effects of coexpressing the plant CDK inhibitor ICK1 and D-type cyclin genes on plant growth, cell size and ploidy in Arabidopsis thaliana. Planta, 216: 604-613. 